\title{
Tingkat Walkability dan Kepuasan Pejalan Kaki di Kawasan Pendidikan Jatinangor dan Kawasan Perdagangan Sudirman
}

\author{
Level of Walkability and Pedestrian Satisfaction in The Jatinangor \\ Educational Areas and The Sudirman Commercial Areas
}

\author{
Vitalani Rahmatiani ${ }^{1}$, Byna Kameswara ${ }^{1}$
}

\begin{abstract}
Abstrak: Walkability merupakan kondisi suatu kawasan yang ramah terhadap pejalan kaki. Untuk mengetahui perbandingan kondisi jalur pejalan kaki dipilih 2 (dua) kawasan dengan guna lahan yang berbeda namun memiliki persamaan karakteristik yaitu pejalan kaki yang tinggi dan permasalahan terkait walkability yang belum teratasi. Penelitian ini bertujuan untuk mengidentifikasikan perbedaan kedua kawasan penelitian dan tingkat kepuasan pengguna jalur pejalan kaki menggunakan Global Walkability Index. Kawasan Pendidikan Jatinangor memiliki nilai 45,5 yang berarti not walkable, sedangkan Kawasan Perdagangan Sudirman memiliki nilai 60,0 yang berarti waiting to walk. Pejalan kaki menunjukan ketidakpuasannya berjalan kaki di Kawasan Pendidikan Jatinangor dan pejalan kaki menunujukan kepuasannya di Kawasan Perdagangan Sudirman. Hal ini mengindikasikan bahwa Kawasan Perdagangan Sudirman lebih walkable dibandingkan Kawasan Pendidikan Jatinangor. Hasil penelitian diharapkan dapat menjadi arahan pengembangan kemampuan lingkungan binaan agar tercapai kawasan yang walkable.
\end{abstract}

Kata kunci: Global Walkability Index, tingkat kepuasan, kawasan pendidikan, kawasan perdagangan dan jasa.

\begin{abstract}
Walkability is a condition in an area that is friendly to pedestrians. To find out the comparison of the conditions of the pedestrian path, 2 (two) areas with different land uses but having the same characteristics are high pedestrians and problems related to walkability that have not been resolved. This study aims to identify the differences between the two research areas and the level of satisfaction of pedestrian users using the Global Walkability Index. The Jatinangor Education Area has a value of 45.5 which means not walkable, while the Sudirman Commercial Area has a value of 60.0 which means waiting to walk. Pedestrians show their dissatisfaction walking in the Jatinangor Education Area and pedestrians show their satisfaction in the Sudirman Commercial Area. This indicates that the Sudirman Commercial Area is more walkable than the Jatinangor Education Area. The results of the research are expected to serve as a direction for the development of the built environment's capacity to achieve a walkable area
\end{abstract}

Keywords: Global Walkability Index, level of satisfaction, educational areas, commercial areas.

\footnotetext{
${ }^{1}$ Jurursan Perencanaan Wilayah dan Kota, ITENAS Bandung
} 


\section{PENDAHULUAN}

New Urban Agenda 2017 merupakan upaya untuk menata dan membangun kotakota Indonesia dalam mengatasi pertumbuhan penduduk dan angka urbanisasi yang setiap tahun meningkat di perkotaan yang mendorong berkembangnya kegiatan di perkotaan dan menimbulkan berbagai permasalah dalam aspek sosial, aspek ekonomi dan aspek lingkungan. Berdasarkan hal tersebut, kota-kota di Indonesia saat ini memiliki tujuan untuk mewujudkan pembangunan perkotaan yang berkelanjutan (Sustainable City) dimana tujuan ini mampu memastikan perwujudan kota-kota dan permukiman yang berkualitas dan berkelanjutan, meliputi pembangunan kota yang terpadu, penyediaan infrastruktur yang layak, aman dan terjangkau bagi semua kalangan serta menyediakan sistem transportasi berkelanjutan. Salah satunya adalah mendorong kebiasaan berjalan kaki melalui peningkatan kualitas infrastruktur pejalan kaki yang aman, layak dan memadai (Kementerian PUPR, 2017). Peningkatan pergerakan dengan berjalan kaki tidak hanya mengurangi permasalahan kemacetan dan polusi tapi juga meningkatkan hubungan antar komunitas perkotaan (Forsyth, 2015; Talen \& Koschinsky, 2013)

Konsep Walkability adalah dasar atau fondasi untuk kota berkelanjutan (Southworth, 2005). Walkability pada dasarnya adalah ukuran tingkat keramahan terhadap pejalan kaki di suatu kawasan dengan tujuan meningkatkan jumlah pejalan kaki agar terwujud transportasi yang berkelanjutan sehingga tercapai juga kota yang berkelanjutan. Walkability dipahami lebih luas tidak hanya sekedar pergerakan dengan berjalan kaki namun juga mengacu pada kemampuan lingkungan binaan dalam mendukung kegiatan berjalan kaki (Moura et al., 2017). Maka dari itu dibutuhkan evaluasi untuk penyediaan fasilitas pejalan kaki yang ramah terhadap pejalan kaki.

Walkability index adalah salah satu metode untuk menilai kondisi kelayakan berjalan yang dikembangkan oleh Krambeck di tahun 2006 dalam bentuk Global Walkability Index yang bertujuan untuk memberikan penilaian tentang kondisi berjalan termasuk keselamatan, keamanan, dan kenyamanan lingkungan pejalan kaki. Terdapat dua kelompok topik yang banyak dibahas dalam penelitian terkait peningkatan kualitas lingkungan binaan dalam mendukung pergerakan berjalan kaki. Pertama adalah topik penelitian terkait pengembangan metode dalam perhitungan kualitas lingkungan yang ramah bagi pejalan kaki. Kedua, terkait dengan pengembangan konsep Walkability sendiri (Ewing \& Handy, 2009; Lwin \& Murayama, 2011).

Walkability dan kinerja suatu lokasi dalam mendukung kegiatan berjalan kaki merupakan fokus penting dalam upaya pembangunan kualitas lingkungan (Hall et al., 2017). Permasalahan yang umum terjadi di perkotaan di Indonesia adalah aspek-aspek terkait walkability masih diabaikan dengan banyaknya kondisi fasilitas pejalan kaki yang tidak memadai. Kondisi keselamatan pejalan kaki di perkotaan mulai terabaikan sedangkan hal yang berkaitan dengan kendaraan bermotor cenderung diperhatikan (Mashuri \& Ikbal, 2011). Permasalahan umum mengenai fasilitas pejalan kaki yang terjadi di Indonesia adalah aktivitas pejalan kaki sebagai pengguna utama belum diwadahi secara maksimal. Fenomena yang sering ditemukan adalah penyalahgunaan fungsi fasilitas pejalan kaki (Mayona et al., 2013).

Kawasan pendidikan memungkinkan munculnya penggunaan lahan campuran dimana para pelajar dapat dengan mudah melakukan aktivitas baik itu perbankan, membeli kebutuhan sehari-hari, berolahraga, dan menghadiri kelas dalam jarak berjalan kaki (Nguyen, 2012). Kawasan pendidikan adalah wilayah fungsional yang memiliki volume pejalan kaki potensial dalam jumlah besar (Firnanda \& Suharyadi, 2015). Statistik kecelakaan menunjukkan bahwa pelajar adalah masyarakat yang rentan terhadap kecelakaan di jalan yang mengindikasikan bahwa sekolah dan perguruan tinggi mungkin tidak memberikan trotoar yang berkualitas atau kurang meyakinkan pemerintah untuk lebih meningkatkan lingkungan pejalan kaki di sekitar kawasan pendidikan (Leather et al, 
2011). Kawasan Pendidikan Jatinangor adalah salah satu kawasan yang ditetapkan sebagai kawasan pendidikan tinggi. Kawasan ini termasuk dalam wilayah Kecamatan Jatinangor, Kabupaten Sumedang. Terdapat 4 (empat) perguruan tinggi di dalam kawasan ini. Tingginya volume pejalan kaki di kawasan ini tidak diimbangi dengan kualitas jalur pejalan kaki yang tersedia. Sebagai kawasan dengan volume pejalan kaki yang tinggi seharusnya didukung oleh kawasan yang mendukung aktivitas pergerakan tersebut.

Kawasan perdagangan dan jasa merupakan pusat kegiatan yang dapat menimbulkan tarikan pergerakan yang tinggi berupa pergerakan kendaraan bermotor dan pejalan kaki (Safitri \& Amelia, 2019). Kawasan perdagangan dan jasa, elemen-elemen seperti hidupnya aktivitas di kawasan serta daya tarik dari kawasan ini harus diperhatikan (Luna \& Ernawati, 2017). Salah satu kawasan perdagangan dan jasa di Kota Bandung adalah di Kawasan Perdagangan Sudirman. Kawasan ini merupakan pusat komersial kota meliputi pusat perdagangan alat-alat kebutuhan rumah tangga, cenderamata dan pusat perbelanjaan kain tekstil terlengkap di Kota Bandung. Pilihan moda yang paling mudah diakses oleh masyarakat ketika berada di kawasan ini dan efisien dalam pengoperasiannya adalah berjalan kaki. Kualitas jaringan pejalan kaki dapat menghambat pejalan kaki meskipun beberapa tempat dapat dijangkau dengan berjalan kaki. Pola ini dapat diubah jika kota menyediakan lingkungan pejalan kaki yang ramah dan aman (Juriah \& Ujang, 2014).

Tujuan dari penelitian ini adalah mengidentifikasi tingkat walkability Kawasan Pendidikan Jatinangor dan Kawasan Perdagangan Sudirman berdasarkan prinsip walkability dan persepsi pengguna jalur pejalan kaki mengenai kepuasan mereka ketika berjalan kaki. Sehingga hasil penelitian dapat menjadi pertimbangan arahan pengembangan kawasan untuk mencapai kawasan yang walkable.

\section{METODE}

\section{Pemilihan Kawasan Penelitian}

Volume pejalan kaki yang tinggi dan guna lahan yang dituju menjadi parameter pemilihan lokasi dalam penelitian. Maka dari itu untuk mengetahui perbandingan kondisi jalur pejalan kaki dipilih 2 (dua) kawasan dengan guna lahan yang berbeda namun memiliki persamaan karakteristik yaitu volume pejalan kaki yang tinggi dan permasalahan terkait walkability yang belum teratasi.

\section{1) Kawasan Pendidikan Jatinangor}

Kawasan Pendidikan Jatinangor termasuk dalam wilayah Kecamatan Jatinangor, Kabupaten Sumedang. Kawasan ini merupakan kawasan di Kabupaten Sumedang yang ditetapkan sebagai kawasan pendidikan tinggi (RTRW Provinsi Jawa Barat 2009-2029). Kehadiran 4 (empat) perguruan tinggi di kawasan ini menjadi daya tarik untuk menginvestasikan sebuah usaha di Jatinangor. Oleh karena itu sering ditemukan pembangunan rumah kos, pusat perbelanjaan, tempat makan, apartemen, jasa, dan lain sebagainya yang bertebaran di sekitar kawasan ini. 


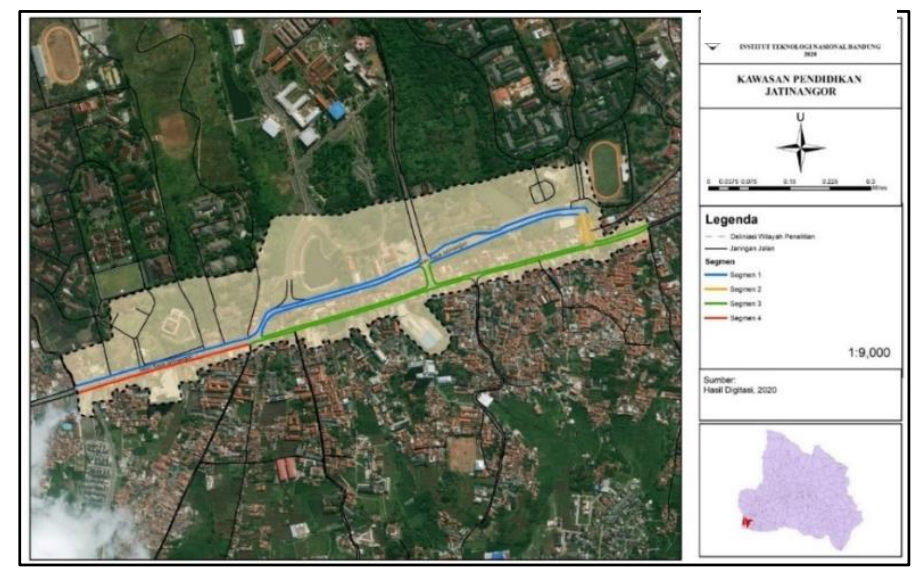

\section{Gambar 1. Kawasan Pendidikan Jatinangor}

\section{Kawasan Perdagangan Sudirman}

Kawasan Perdagangan Sudirman termasuk dalam Kecamatan Andir, Kecamatan Sumur Bandung, Kecamatan Astana Anyar, dan Kecamatan Regol, Kota Bandung. Kawasan ini merupakan salah satu pusat perdagangan dan jasa di Kota Bandung (RDTR Kota Bandung 2015-2035). Kawasan Perdagangan Sudirman merupakan kawasan perdagangan yang berlokasi strategis di Kota Bandung. Secara fisik, kegiatan perdagangan dan jasa tersebar di sekitar kawasan ini.

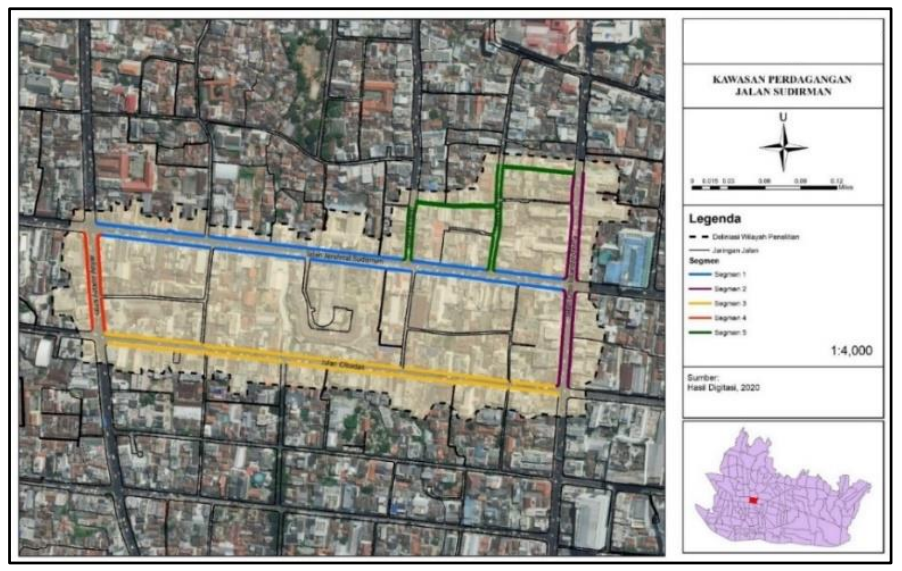

\section{Gambar 2. Kawasan Perdagangan Sudirman}

\section{Metode Pengumpulan Data}

Pengumpulan data diperlukan untuk mendapatkan data-data yang dibutuhkan sebagai input dalam melakukan proses analisa. Metode pengumpulan data yang digunakan dalam penelitian ini adalah observasi lapangan dan penyebaran kuesioner terhadap responden yaitu pejalan kaki. 
Observasi dilakukan untuk mengidentifikasi kondisi walkability. Pembagian segmen setiap kawasan dibagi berdasarkan perbedaan karakter fisik pada setiap jalur pejalan kaki dimana hal ini akan mempengaruhi perbedaan kualitas jalur pejalan kaki. Untuk mengetahui karakteristik pejalan kaki dan tingkat kepuasan pejalan kaki menggunakan kuesioner online. Besar sampel minimum untuk penelitian deskriptif disarankan sebanyak 100 unit sampel (Fraenkel \& Wallen, 1993). Setiap lokasi penelitian mengambil sampel berjumlah 100 orang. Maka total sampel pada penelitian ini adalah 200 orang.

\section{Lokasi Pengamatan}

Pengamatan dilakukan di jalur pejalan kaki yang memiliki volume pejalan kaki yang tinggi dan menempel dengan fungsi kawasan penelitian. Kawasan penelitian dibagi menjadi beberapa segmen berdasarkan kondisi fisik jalur pejalan kakinya dan jenis aktivitasnya.

\section{Metode Analisis}

\section{1) Statistik Deskriptif}

Digunakan untuk menganalisa karakteristik pejalan kaki di kawasan penelitian yang terdiri atas jenis kelamin, usia, pekerjaan, tujuan pejalan kaki berjalan di kawasan penelitian, dan moda transportasi yang digunakan sebelum melakukan aktivitas berjalan kaki. Statistik deskriptif adalah statistik yang digunakan untuk menganalisis data dengan cara mendeskripsikan atau menggambarkan data yang telah terkumpul sebagaimana adanya tanpa bermaksud membuat kesimpulan yang berlaku untuk umum atau generalisasi dengan penyajian data dapat melalui diagram lingkaran (Sugiyono, 2010).

\section{2) Global Walkability Index (GWI)}

Bertujuan untuk meningkatkan walkability di kota-kota berkembang agar bisa memberikan kenyamanan dalam berjalan (Krambeck, 2006). Berikut merupakan parameter beserta deskripsi pengukuran menggunakan Global Walkability Index. Perhitungan walkability index dalam "Walkability Surveys in Asian Cities" yang dilakukan oleh Sudhir Gota tahun 2011, mempertimbangkan bobot yang diterapkan pada parameter survei lapangan agar mempertimbangkan kepentingan setiap parameter. Ditunjukkan pada Tabel 1.

Tabel 1. Variabel dan Parameter Global Walkability Index

\begin{tabular}{|c|c|c|c|}
\hline Variabel & Parameter & Bobot & Penjelasan \\
\hline \multirow{3}{*}{$\begin{array}{l}\text { Keselamatan } \\
\text { dan keamanan }\end{array}$} & $\begin{array}{l}\text { Konflik jalur pejalan kaki } \\
\text { dengan moda transportasi lain }\end{array}$ & 15 & $\begin{array}{l}\text { Adanya konflik antara pejalan kaki dan } \\
\text { moda lain di jalan seperti sepeda, sepeda } \\
\text { motor dan mobil }\end{array}$ \\
\hline & Keamanan terhadap kejahatan & 5 & $\begin{array}{l}\text { Penilaian terhadap keamanan dari } \\
\text { kejahatan pada lingkungan sekitar jalur } \\
\text { pejalan kaki. }\end{array}$ \\
\hline & Keamanan penyeberangan & 10 & $\begin{array}{l}\text { Keamanan terhadap pejalan kaki } \\
\text { terhadap moda transortasi lain ketika } \\
\text { menyebrang dan waktu yang dibutuhkan } \\
\text { untuk menyebrang }\end{array}$ \\
\hline \multirow{4}{*}{$\begin{array}{l}\text { Kenyamanan } \\
\text { dan daya tarik }\end{array}$} & Perilaku pengendara & 5 & Sikap pengendara terhadap pejalan kaki \\
\hline & Amenitas (fasilitas pendukung) & 10 & $\begin{array}{l}\text { Ketersediaan fasilitas pejalan kaki seperti } \\
\text { bangku, lampu jalan, toilet umum, dan } \\
\text { pohon-pohon yang mempunyai pengaruh } \\
\text { dalam kenyamanan dan minat untuk } \\
\text { berjalan kaki }\end{array}$ \\
\hline & $\begin{array}{l}\text { Infrastruktur penunjang } \\
\text { kelompok penyandang cacat }\end{array}$ & 10 & $\begin{array}{l}\text { Ketersediaan, posisi dan pemeliharan } \\
\text { infrastruktur untuk penyandang cacat di } \\
\text { jalur pejalan kaki }\end{array}$ \\
\hline & Ketersediaan jalur pejalan kaki & 25 & $\begin{array}{l}\text { Ketersediaan dan kondisi jalur pejalan } \\
\text { kaki }\end{array}$ \\
\hline
\end{tabular}




\begin{tabular}{|c|c|c|c|}
\hline Variabel & Parameter & Bobot & Penjelasan \\
\hline & Kendala/hambatan & 10 & $\begin{array}{l}\text { Adanya penghalang permanen dan } \\
\text { sementara di jalur pejalan kaki yang } \\
\text { berpengaruh kepada kenyamanan }\end{array}$ \\
\hline & & & $\begin{array}{l}\text { berjalan terhadap lebar efektif jalur } \\
\text { pejalan kaki. }\end{array}$ \\
\hline & Ketersediaan penyeberangan & 10 & $\begin{array}{l}\text { Ketersediaan dan tempat penyeberangan } \\
\text { untuk pejalan kaki }\end{array}$ \\
\hline
\end{tabular}

Sumber: Krambeck (2006), Gota (2011)

\section{3) Analisis Regresi}

Analisis regresi merupakan metode analisis untuk mencari tahu pengaruh dari dua atau lebih variabel bebas (independen atau X) terhadap variabel terikat (dependen atau Y) dan memprediksi besar nilai variabel terikat jika variabel bebas mengalami kenaikan atau penurunan.

Setelah itu dilakukan analisis untuk mengetahui perbandingan kondisi walkability berdasarkan rata-rata tingkat walkability dan kepuasan pejalan kaki di 2 (dua) kawasan penelitian yang diolah di software SPSS.

\section{HASIL DAN PEMBAHASAN}

\section{Jalur Pejalan Kaki Kawasan Penelitian}

Penelitian dilakukan pada setiap segmen kawasan penelitian. Kawasan Pendidikan Jatinangor terbagi menjadi 4 segmen sedangkan Kawasan Perdagangan Sudirman terbagi menjadi 5 segmen yang dibagi berdasarkan jenis aktivitas di kawasan. Berikut ini adalah kondisi jalur pejalan kaki di kawasan penelitian.

Tabel 2. Jalur Pejalan Kaki Kawasan Penelitian

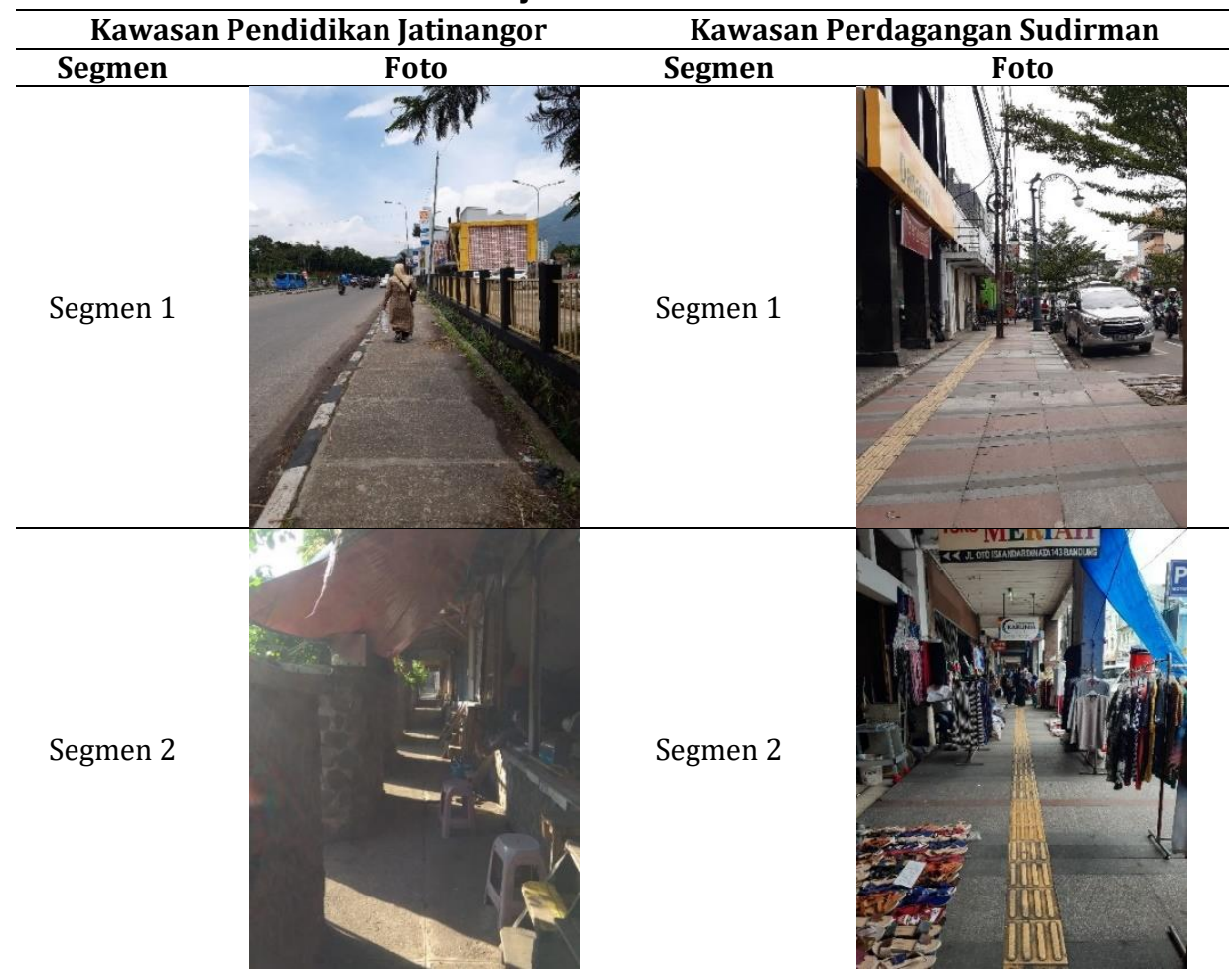




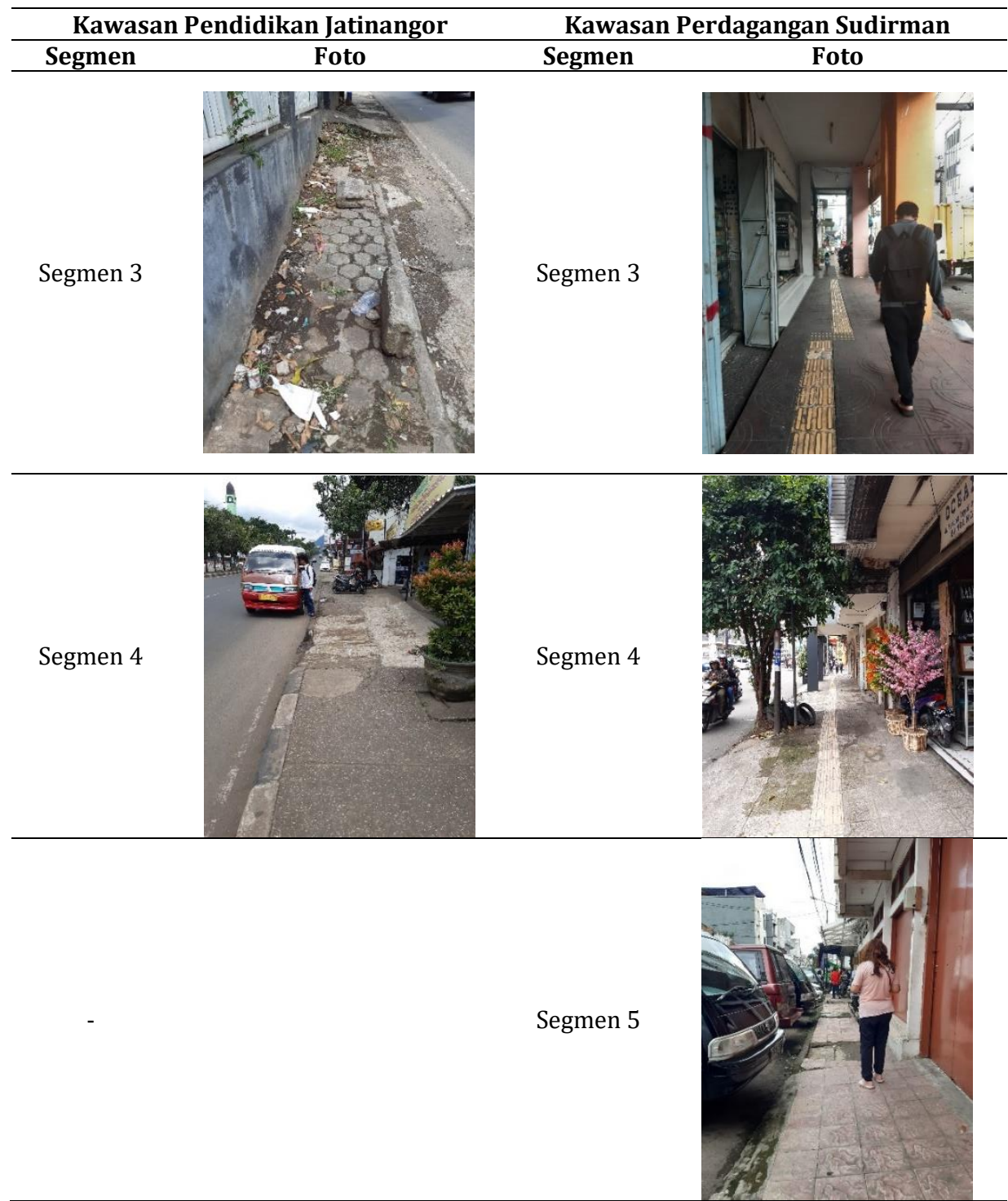

Sumber: Hasil Survei Primer, 2020

\section{Karakteristik Pejalan Kaki di Kawasan Pendidikan Jatinangor}

Berdasarkan gambar 3 dapat diketahui bahwa responden yang berjalan kaki di Kawasan Pendidikan Jatinangor didominasi oleh wanita dengan persentase 58\% dari total seluruh responden dengan seluruh responden termasuk kelompok usia 15-30 tahun. Hal tersebut dikarenakan rata-rata responden merupakan mahasiswa perguruan-perguruan tinggi di kawasan ini. Jumlah responden dengan pekerjaan sebagai pelajar/mahasiswa adalah yang terbanyak dengan persentase $89 \%$ dari total seluruh responden. Selanjutnya $74 \%$ responden yang berjalan kaki di kawasan ini memiliki tujuan perjalanan sekolah. Moda yang digunakan responden didominasi oleh penggunaan transportasi publik dengan persentase 33\% dimana transportasi publik ini berupa Bus DAMRI, travel dan angkutan kota. 


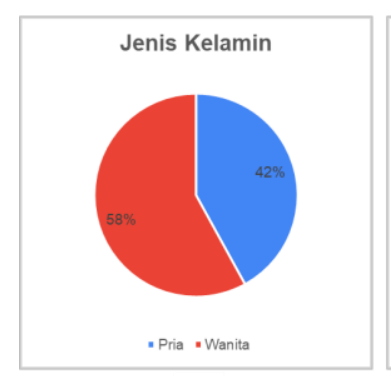

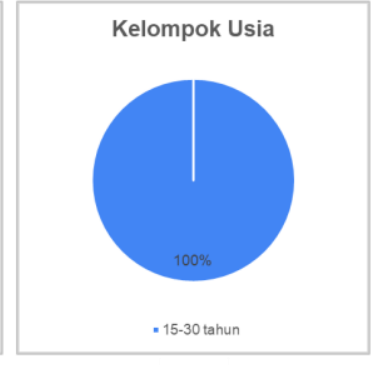
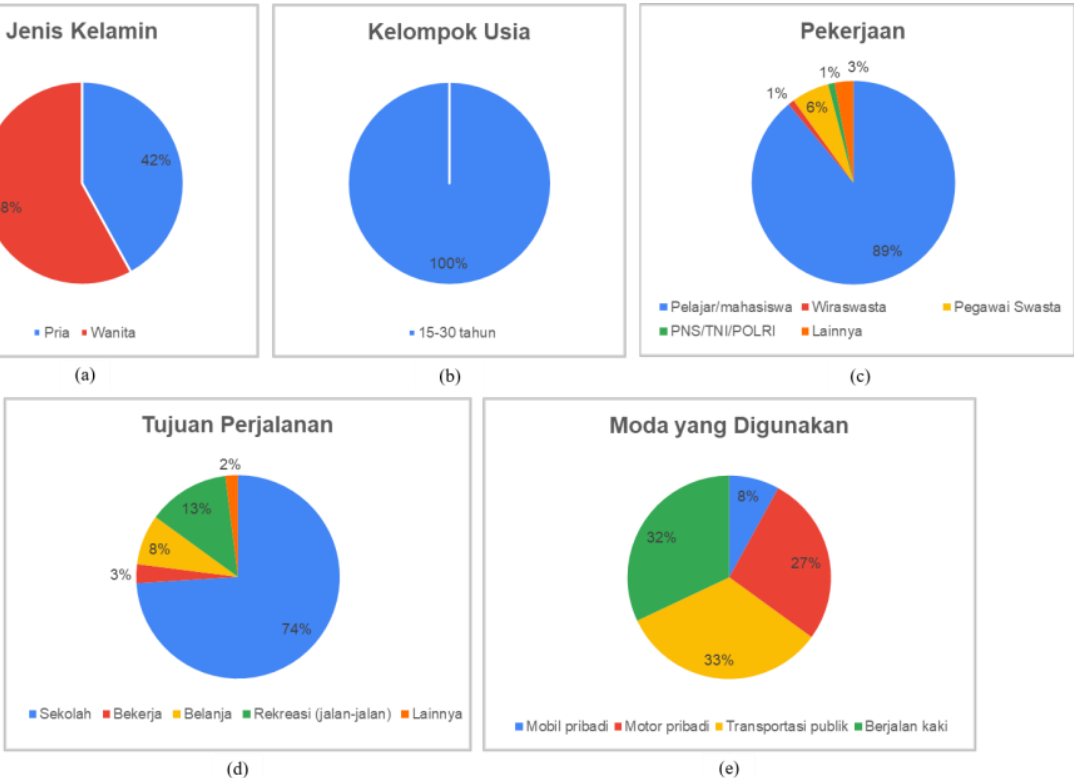

Gambar 3. Karakteristik Pejalan Kaki di Kawasan Pendidikan Jatinangor (a) Jenis Kelamin, (b) Usia, (c) Pekerjaan, (d) Tujuan Perjalanan, (e) Moda yang Digunakan

Karakteristik Pejalan Kaki di Kawasan Perdagangan Sudirman

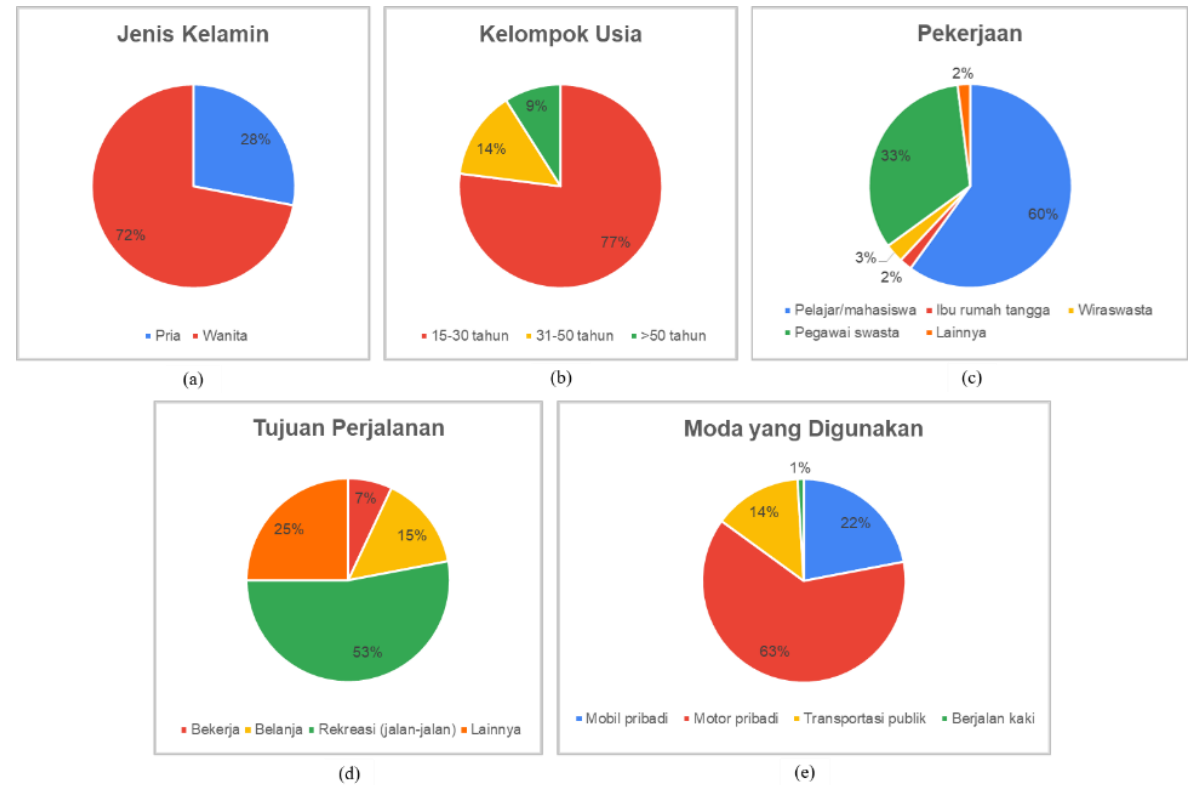

Gambar 4. Karakteristik Pejalan Kaki di Kawasan Perdagangan Sudirman (a) Jenis Kelamin, (b) Usia, (c) Pekerjaan, (d) Tujuan Perjalanan, (e) Moda yang Digunakan

Berdasarkan gambar 4 dapat diketahui bahwa responden yang berjalan kaki di Kawasan Perdagangan Sudirman didominasi oleh wanita dengan persentase $72 \%$ dari total seluruh responden dengan 77\% responden adalah kelompok usia 15-30 tahun. Hal tersebut 
dikarenakan rata-rata responden merupakan responden merupakan pelaku pasar (penjual dan pembeli) atau pekerja di kawasan ini. Jumlah responden dengan pekerjaan sebagai pelajar/mahasiswa adalah yang terbanyak dengan persentase $60 \%$ dari total seluruh responden. Selanjutnya 53\% responden yang berjalan kaki di kawasan ini memiliki tujuan perjalanan rekreasi (jalan-jalan). Moda yang digunakan didominasi oleh penggunaan transportasi pribadi berupa motor pribadi dengan persentase $63 \%$.

\section{Nilai Walkability}

Dari masing-masing kondisi jalur pejalan kaki setiap segmen, maka disimpulkan penilaian tingkat walkability dalam tabel di bawah ini beserta dengan nilai parameter masing-masing untuk mendapat walkability score.

Tabel 3. Penilaian WalkabilityKawasan Pendidikan Jatinangor

\begin{tabular}{|c|c|c|c|c|c|c|c|}
\hline \multirow{2}{*}{ No } & \multirow{2}{*}{ Parameter } & \multirow{2}{*}{ Bobot } & \multicolumn{4}{|c|}{ Segmen } & \multirow{2}{*}{$\mathbf{W I}$} \\
\hline & & & 1 & 2 & 3 & 4 & \\
\hline 1 & $\begin{array}{l}\text { Konflik jalur pejalan kaki } \\
\text { dengan moda transportasi lain }\end{array}$ & 15 & 4 & 5 & 1 & 4 & 70 \\
\hline 2 & Keamanan terhadap kejahatan & 5 & 1 & 3 & 1 & 3 & 40 \\
\hline 3 & Keamanan penyeberangan & 10 & 1 & 1 & 2 & 2 & 30 \\
\hline 4 & Perilaku pengendara & 5 & 2 & 2 & 2 & 2 & 40 \\
\hline 5 & $\begin{array}{l}\text { Amenities (fasilitas } \\
\text { pendukung) }\end{array}$ & 10 & 2 & 1 & 2 & 1 & 30 \\
\hline 6 & $\begin{array}{l}\text { Infrastruktur penunjang } \\
\text { kelompok penyandang cacat }\end{array}$ & 10 & 1 & 1 & 1 & 1 & 20 \\
\hline 7 & Ketersediaan jalur pejalan kaki & 25 & 4 & 3 & 1 & 4 & 60 \\
\hline 8 & Kendala/hambatan & 10 & 4 & 2 & 1 & 5 & 60 \\
\hline 9 & Ketersediaan penyeberangan & 10 & 1 & 1 & 1 & 1 & 20 \\
\hline \multicolumn{3}{|c|}{ Walkability Score } & & & & & 45,50 \\
\hline
\end{tabular}

Dapat diketahui bahwa Kawasan Pendidikan Jatinangor memiliki walkability score sebesar 45,50 yang berarti kawasan ini masuk ke dalam kategori not walkable atau tidak baik untuk berjalan kaki dan memiliki lingkungan yang tidak ramah terhadap pejalan kaki.

Tabel 4. Penilaian WalkabilityKawasan Perdagangan Sudirman

\begin{tabular}{|c|c|c|c|c|c|c|c|c|}
\hline \multirow{2}{*}{ No } & \multirow{2}{*}{ Parameter } & \multirow{2}{*}{ Bobot } & \multicolumn{5}{|c|}{ Segmen } & \multirow{2}{*}{ WI } \\
\hline & & & 1 & 2 & 3 & 4 & 5 & \\
\hline 1 & $\begin{array}{l}\text { Konflik jalur pejalan kaki dengan } \\
\text { moda transportasi lain }\end{array}$ & 15 & 4 & 5 & 4 & 4 & 3 & 80 \\
\hline 2 & Keamanan terhadap kejahatan & 5 & 3 & 2 & 2 & 3 & 3 & 52 \\
\hline 3 & Keamanan penyeberangan & 10 & 3 & 3 & 4 & 4 & 4 & 72 \\
\hline 4 & Perilaku pengendara & 5 & 4 & 4 & 3 & 3 & 3 & 68 \\
\hline 5 & Amenities (fasilitas pendukung) & 10 & 5 & 2 & 2 & 2 & 2 & 52 \\
\hline 6 & $\begin{array}{l}\text { Infrastruktur penunjang kelompok } \\
\text { penyandang cacat }\end{array}$ & 10 & 5 & 2 & 2 & 3 & 1 & 52 \\
\hline 7 & Ketersediaan jalur pejalan kaki & 25 & 4 & 2 & 2 & 3 & 3 & 56 \\
\hline 8 & Kendala/hambatan & 10 & 4 & 2 & 2 & 3 & 2 & 52 \\
\hline 9 & Ketersediaan penyeberangan & 10 & 2 & 4 & 1 & 4 & 2 & 52 \\
\hline \multicolumn{8}{|c|}{ Walkability Score } & 60,00 \\
\hline
\end{tabular}

Dapat diketahui bahwa Kawasan Perdagangan Sudirman memiliki walkability score sebesar 60,0 yang berarti kawasan ini masuk ke dalam kategori waiting to walk atau cukup baik untuk berjalan kaki dan secara umum perlu ditingkatkan untuk mencapai fungsi optimal. 
Hasil penilaian walkability terhadap 9 parameter untuk setiap kawasan ditunjukkan Gambar 13. Nilai walkability berdasarkan penilaian peneliti dan bobot setiap parameter, nilai tertinggi untuk Kawasan Pendidikan Jatinangor diperoleh pada parameter 1 (konflik jalur pejalan kaki dengan moda transportasi lain), sebaliknya nilai terendah pada parameter 6 (infrastruktur penunjang kelompok penyandang cacat) dan 9 (ketersediaan jalur pejalan kaki).

Seperti Kawasan Pendidikan Jatinangor, Kawasan Perdagangan Sudirman memiliki nilai walkability tertinggi diperoleh parameter 1 (konflik jalur pejalan kaki dengan moda transportasi lain), sedangkan terendah diperoleh parameter 2 (keamanan terhadap kejahatan), parameter 5 (amenitas), parameter 6 (infrastruktur penunjang kelompok penyandang cacat), parameter 8 (kendala/hambatan) dan parameter 9 (ketersediaan jalur pejalan kaki).

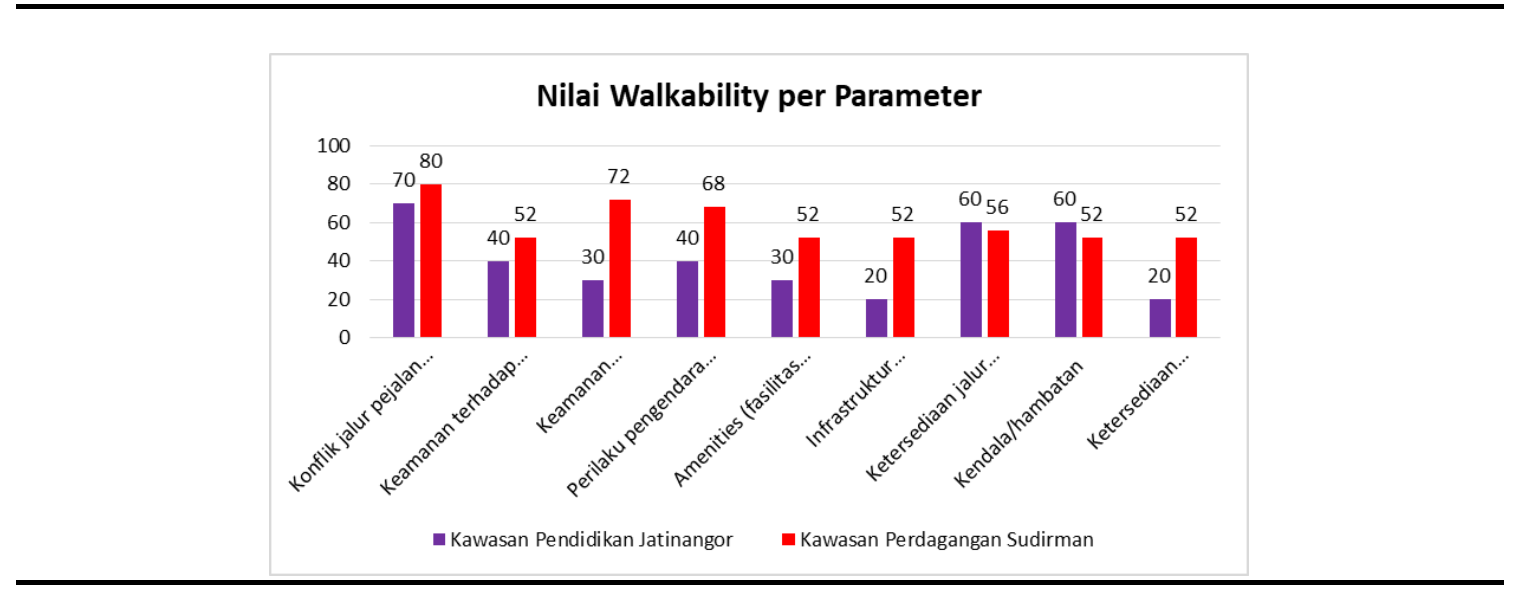

Gambar 5. Perbandingan Tingkat Walkability

\section{Tingkat Kepuasan Pejalan Kaki}

Penilaian tingkat kepuasan yang dilakukan oleh responden dimana responden diminta untuk memberi penilaian mengenai tingkat kepuasan mereka terhadap jalur pejalan kaki. Penilaian dalam kuesioner ini memiliki 5 skala yaitu sangat puas (5), puas (4), netral (3), tidak puas (2), dan sangat tidak puas (1). Hasil penilaian kepuasan pejalan kaki terhadap 9 parameter untuk setiap kawasan ditunjukkan Gambar 14.

Berdasarkan hasil kuesioner, Kawasan Pendidikan Jatinangor nilai kepuasan tertinggi diperoleh parameter 4 (perilaku pengendara). Sedangkan nilai kepuasan terendah diperoleh parameter 6 (infrastruktur penunjang kelompok penyandang cacat). Namun penilaian kepuasan yang diberikan oleh responden secara keseluruhan adalah 1,96 dan nilai kepuasan setiap parameter menunjukan angka dibawah 3 yang berarti pejalan kaki menunjukan ketidakpuasannya terhadap seluruh parameter walkability di kawasan ini. Terkait dengan kawasan pendidikan dimana pelajar/mahasiswa sebagai mayoritas pejalan kakinya, infrastruktur penunjang penyandang cacat yang minim pada kawasan ini membuktikan bahwa penyandang cacat masih terabaikan.

Selanjutnya, untuk Kawasan Perdagangan Sudirman nilai kepuasan tertinggi diperoleh parameter 5 (amenitas). Sedangkan nilai kepuasan terendah diperoleh parameter 8 (kendala/hambatan). Berdasarkan penilaian kepuasan yang diberikan oleh responden menunjukan bahwa mereka menunjukan kepuasannya dengan nilai secara keseluruhan yaitu 3,16 dan nilai kepuasan setiap parameter yang memiliki nilai di atas 3 yaitu parameter 1 (konflik jalur pejalan kaki dengan moda transportasi lain), parameter 2 
(keamanan terhadap kejahatan), parameter 5 (amenitas), parameter 7 (ketersediaan jalur pejalan kaki), dan parameter 9 (ketersediaan penyeberangan).

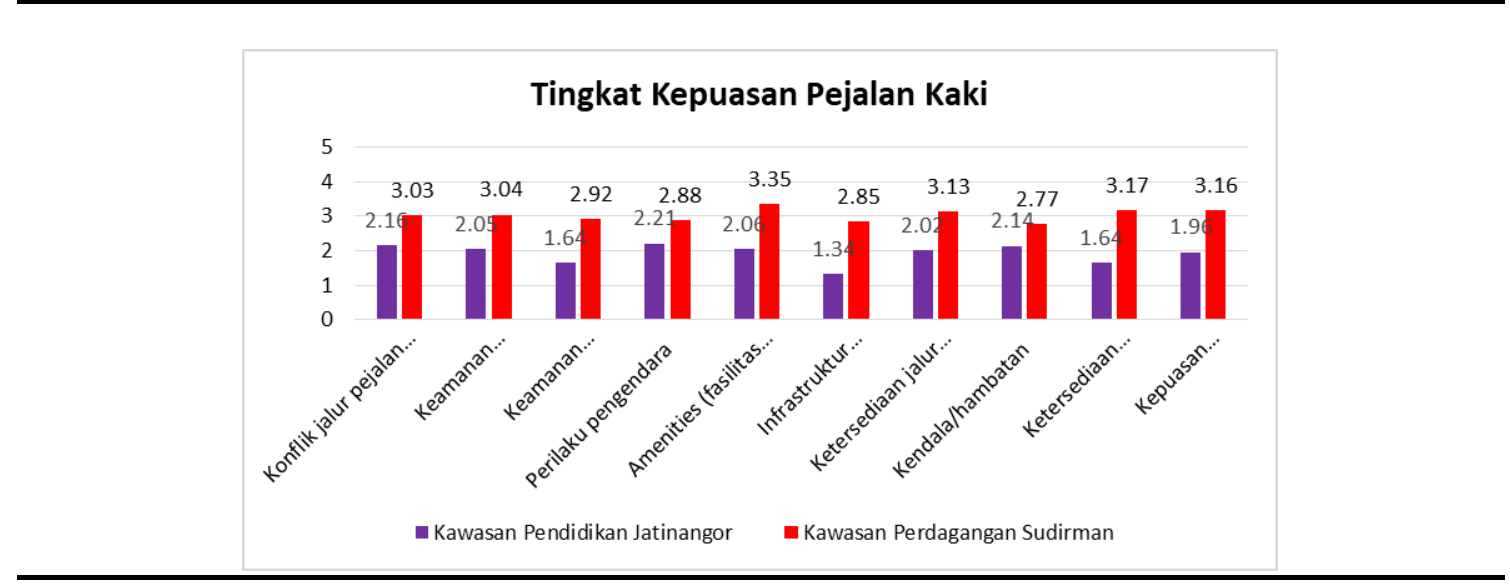

Gambar 6. Perbandingan Tingkat Kepuasan

\section{Variabel yang mempengaruhi kepuasan pejalan kaki}

Berdasarkan analisis regresi yang dilakukan diperoleh perbedaan variabel yang mempengaruhi kepuasan masyarakat berjalan di 2 (dua) kawasan penelitian. Dilihat dari uji hipotesis secara parsial (uji t) seperti yang tertera di tabel 2 ditemukan bahwa kedua variabel berpengaruh terhadap kepuasan pejalan kaki di Kawasan Pendidikan Jatinangor. Kawasan Perdagangan Sudirman variabel yang berpengaruh signifikan adalah variabel kenyamanan dan daya tarik, sedangkan variabel keamanan dan keselamatan merupakan variabel yang tidak berpengaruh terhadap kepuasan pejalan kaki.

Tabel 5. Uji T dan Model Regresi

\begin{tabular}{|c|c|c|c|c|c|c|}
\hline \multirow[b]{2}{*}{ Model } & \multicolumn{3}{|c|}{$\begin{array}{l}\text { Kawasan Pendidikan Jatinangor } \\
\text { Standardized } \\
\text { Coefficients }\end{array}$} & \multicolumn{3}{|c|}{$\begin{array}{l}\text { Kawasan Perdagangan Sudirman } \\
\text { Standardized }\end{array}$} \\
\hline & Beta & $\mathbf{t}$ & Sig. & Beta & $\mathbf{t}$ & Sig. \\
\hline (Constant) & & -.511 & .610 & & .745 & .458 \\
\hline $\mathrm{X} 1$ & .248 & 2.817 & .006 & .057 & .650 & .517 \\
\hline $\mathrm{X} 2$ & .533 & 6.064 & .000 & .608 & 6.892 & .000 \\
\hline
\end{tabular}

Dapat disimpulkan di Kawasan Pendidikan Jatinangor, X1 (Variabel Keselamatan dan Keamanan) dan X2 (Variabel Kenyamanan dan Daya Tarik) berpengaruh positif dan signifikan terhadap kepuasan pejalan kaki. Hal ini dapat ditunjukkan dengan nilai signifikansi (P Value) yang lebih kecil dari 0,05 serta nilai koefisien regresi yang nilainya positif. Dimana semakin tinggi kedua variabel diterapkan di jalur pejalan kaki, maka akan semakin tinggi pula kepuasan pejalan kakinya. Selanjutnya di Kawasan Perdagangan Sudirman, X1 (Variabel Keselamatan dan Keamanan) berpengaruh positif namun tidak signifikan terhadap kepuasan pejalan kaki. Sedangkan X2 (Variabel Kenyamanan dan Daya Tarik) berpengaruh positif dan signifikan terhadap kepuasan pejalan kaki. 


\section{Perbandingan Tingkat Walkabilitydengan Kepuasan Pejalan Kaki di Kawasan Pendidikan Jatinangor dan Kawasan Perdagangan Sudirman}

Analisis perbandingan nilai walkability (X) dengan tingkat kepuasan pejalan kaki (Y) terhadap nilai rata-rata kedua variabel Global Walkability Index menggunakan diagram kartesius. Diagram ini memungkinkan untuk mengetahui perbandingan kondisi walkability berdasarkan rata-rata tingkat walkability dan kepuasan pejalan kaki di 2 (dua) kawasan penelitian.

Tabel 6. Rata-rata Skoring

\begin{tabular}{lcc}
\hline \multicolumn{1}{c}{ Variabel } & $\begin{array}{c}\text { Nilai } \\
\text { Walkability (X) }\end{array}$ & $\begin{array}{c}\text { Kepuasan Pejalan } \\
\text { Kaki (Y) }\end{array}$ \\
\hline Keselamatan dan keamanan & 2,79 & 2,49 \\
Kenyamanan dan daya tarik & 2,26 & 2,45 \\
Rata-rata & $\mathbf{2 , 5 2}$ & $\mathbf{2 , 4 7}$ \\
\hline
\end{tabular}

Hasil perhitungan di atas adalah titik penentu garis tengah dimana titik X adalah 2,52 dan titik Y adalah 2,47. Kemudian dilakukan pengolahan data variabel walkability berdasarkan hasil skoring yang dilakukan peneliti dan skoring kepuasan yang dilakukan responden untuk dijadikan diagram kartesius yang diolah di software SPSS. Diagram kartesius yang telah diolah di SPSS dapat dilihat pada Gambar 7.

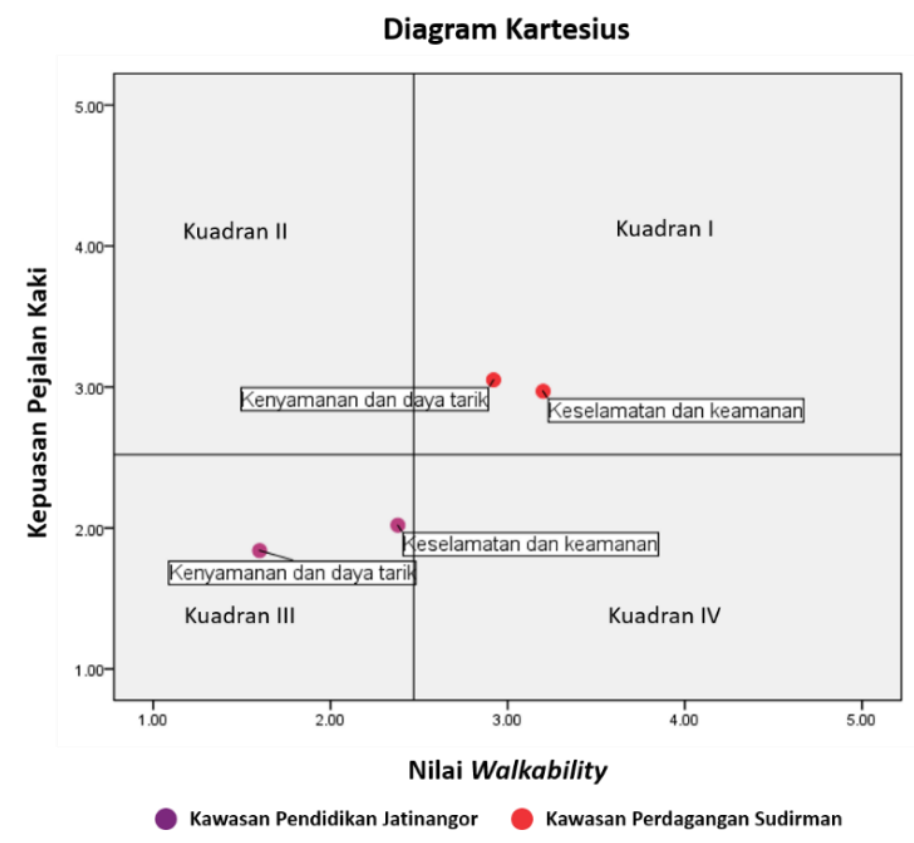

Gambar 7. Diagram Kartesius Walkability terhadap Kepuasan Pejalan Kaki

Berdasarkan diagram diatas, maka dapat diketahui bahwa terdapat 2 (dua) kuadran yang terisi. Pertama, Kuadran I memiliki variabel keselamatan dan keamanan serta variabel kenyamanan dan daya tarik di Kawasan Perdagangan Sudirman yang berarti kedua variabel memiliki tingkat walkability dan tingkat kepuasan di atas rata-rata. Hal ini menunjukan bahwa secara umum kepuasan pejalan kaki terhadap variabel variabel keselamatan dan keamanan serta variabel kenyamanan dan daya tarik di kawasan ini sudah berada di atas rata-rata kondisi walkability di 2 (dua) kawasan penelitian. 
Kedua yaitu Kuadran III memiliki variabel keselamatan dan keamanan serta variabel kenyamanan dan daya tarik di Kawasan Pendidikan Jatinangor yang berarti kedua variabel memiliki tingkat walkability dan tingkat kepuasan di bawah rata-rata. Hal ini menunjukan bahwa secara umum kepuasan pejalan kaki terhadap variabel keselamatan dan keamanan serta variabel kenyamanan dan daya tarik di kawasan ini masih berada di bawah rata-rata kondisi walkability di 2 (dua) kawasan penelitian.

\section{PEMBAHASAN}

Berdasarkan hasil penelitian, maka dapat disimpulkan bahwa Kawasan Pendidikan Jatinangor termasuk dalam kawasan yang berkriteria not walkable dengan nilai walkability 45,50 atau berarti kawasan ini belum ramah pejalan kaki dan didukung oleh persepsi pejalan kaki yang menunjukan ketidakpuasan terhadap kondisi jalur pejalan kaki di Kawasan Pendidikan Jatinangor. Sedangkan Kawasan Perdagangan Sudirman merupakan kawasan dengan kriteria waiting to walk dengan nilai 60,0 dan pejalan kaki menunjukan kepuasannya ketika berjalan kaki di Kawasan Perdagangan Sudirman.

Kawasan Pendidikan Jatinangor memiliki tingkat walkability yang lebih rendah jika dibandingkan dengan penelitian yang dilakukan di kawasan pendidikan di Kota Semarang dan kota-kota di Asia yang menunjukan bahwa kawasan pendidikan memiliki nilai walkability $>50$. Hal ini mengindikasikan bahwa Kawasan Pendidikan Jatinangor masih memiliki tingkat walkability yang kurang jika dibandingkan kawasan pendidikan lainnya. Sedangkan berdasarkan hasil analisis regresi ditemukan bahwa variabel keamanan dan keselamatan merupakan variabel yang cukup signifikan dalam mempengaruhi kepuasan para pejalan kaki di Kawasan Pendidikan Jatinangor.

Kawasan Perdagangan Sudirman memiliki tingkat walkability yang sama dengan penelitian yang dilakukan yang dilakukan di kota-kota di Asia dan Kota Semarang, kawasan perdagangan dan jasa memiliki kriteria waiting to walk (Leather et al, 2011; Tanan et al, 2017) yang mengindikasikan bahwa kawasan perdagangan dan jasa belum sepenuhnya ramah pejalan kaki. Hasil analisis regresi menunjukan bahwa variabel yang cukup signifikan mempengaruhi kepuasan pejalan kaki adalah variabel keamanan dan kenyamanan. Perbedaan hasil identifikasi di 2 (dua) kawasan penelitian ini dapat dipengaruhi oleh karakteristik/ciri khas yang dimiliki setiap fungsi kawasan.

\section{KESIMPULAN}

Kawasan Pendidikan Jatinangor merupakan kawasan yang not walkable dan para pejalan kaki menunjukan ketidakpuasannya terhadap kondisi jalur pejalan kaki di kawasan ini. Sedangkan Kawasan Perdagangan Sudirman merupakan kawasan dengan kategori waiting to walk dan pejalan kaki menunjukan kepuasannya ketika berjalan di ini. Maka dapat disimpulkan bahwa Kawasan Perdagangan Sudirman memiliki kondisi yang lebih ramah pejalan kaki dibandingkan Kawasan Pendidikan Jatinangor. Meskipun demikian masih terdapat parameter-parameter walkability yang perlu dibenahi berdasarkan hasil penelitian agar kedua kawasan ini menjadi kawasan yang ramah pejalan kaki dan dapat mendukung tercapainya New Urban Agenda 2017.

\section{DAFTAR PUSTAKA}

Ewing, R., \& Handy, S. (2009). Measuring the unmeasurable: Urban design qualities related to walkability. Journal of Urban Design, 14(1), 65-84.

Firnanda, A. N., \& Suharyadi, R. (2015). Kajian Penilaian Kondisi Jalur Pedestrian dengan Menggunakan Indeks Walkability (Kenyamanan Pejalan Kaki) di Kawasan Pendidikan YOGYAKARTA. Jurnal Bumi Indonesia, 4(1), 222882. 
Forsyth, A. (2015). What is a walkable place? The walkability debate in urban design. Urban Design International, 20(4), 274-292.

Fraenkel, J. R., \& Wallen, N. E. \& Hyun, H. H. (1993). How to Design and Evaluate Research in Education (Vol. 7). New York: McGraw-Hill.

Gota, S., Fabian, H. G., Mejia, A. A., \& Punte, S. S. (2010). Walkability surveys in Asian cities. Clean Air Initiative for Asian Cities (CAI-Asia)., 20. http://www.ictct.org/migrated_2014/ictct_document_nr_663_102A Sophie Sabine Punte Walkability Surveys in Asian Cities.pdf

Hall, C. M., Ram, Y., \& Shoval, N. (2017). The Routledge international handbook of walking. Routledge.

Juriah, Z., \& Ujang, N. (2014). Comfort of Walking in the City Center of Kuala Lumpur.

Kementerian PUPR. (2017). Panduan Praktis Implementasi Agenda Baru Perkotaan - New Urban agenda. Journal of Chemical Information and Modeling. https://doi.org/10.1017/CB09781107415324.004

Krambeck, H. V. (2006). The global walkability index. Massachusetts Institute of Technology.

Leather James, Fabian Herbert, Gota Sudhir, M. A. (2011). Walkability and Pedestrian Facilities in Asian Cities. Asian Development Bank.

Luna, C., \& Ernawati, J. (2017). Kualitas Walkability pada Koridor Jalan Kayu Aya Seminyak Bali (Issue 0341).

Lwin, K. K., \& Murayama, Y. (2011). Modelling of urban green space walkability: Eco-friendly walk score calculator. Computers, Environment and Urban Systems, 35(5), 408-420.

Mashuri, M., \& Ikbal, M. (2011). Studi Karakteristik Pejalan Kaki dan Pemilihan Jenis Fasilitas Penyeberangan Pejalan Kaki di Kota Palu (Studi Kasus: Jl. Emmi Saelan Depan Mal Tatura Kota Palu). Jurnal Rekayasa Dan Manajemen Transportasi, 1(2).

Mayona, E. L., Moravian, A., \& Azhari, R. (2013). Identifikasi Kebutuhan Fasilitas Pejalan Kaki di Kota Pontianak. Reka Loka, xx(x), 1-9.

Moura, F., Cambra, P., \& Gonçalves, A. B. (2017). Measuring walkability for distinct pedestrian groups with a participatory assessment method: A case study in Lisbon. Landscape and Urban Planning, 157, 282-296.

Nguyen, L. H. (2012). Walkability at Wright State University. Master of Public Health Program Student Publication.

Badan Perencanaan Pembangunan Daerah Provinsi Jawa Barat. 2010. Rencana Tata Ruang Wilayah Provinsi Jawa Barat 2009-2029. Provinsi Jawa Barat.

Pemerintah Kota Bandung. 2015. Peraturan Daerah Kota Bandung No. 10 Tahun 2015 Tentang Rencana Detail Tata Ruang Dan Peraturan Zonasi Kota Bandung Tahun 2015 - 2035. Bandung.

Safitri, R., \& Amelia, R. (2019). Walkability Index in Commercial Area of Pangkalpinang City. In Jurnal Infrastruktur (Vol. 5, Issue 2, pp. 79-83). https://doi.org/10.35814/infrastruktur.v5i2.1009

Southworth, M. (2005). Designing the walkable city. Journal of Urban Planning and Development, 131(4), 246257.

Sugiyono, S. (2010). Metode penelitian kuantitatif dan kualitatif dan R\&D. ALFABETA Bandung.

Talen, E., \& Koschinsky, J. (2013). The walkable neighborhood: A literature review. International Journal of Sustainable Land Use and Urban Planning, 1(1).

Tanan, N., Wibowo, S. S., \& Tinumbia, N. (2017). Pengukuran Walkability Index Pada Ruas Jalan Di Kawasan Perkotaan. In Jalan-Jembatan (Vol. 34, Issue 2, pp. 115-127). 